Cuadernos de Filología Clásica. Estudios Latinos

ISSN: 1131-9062

http://dx.doi.org/10.5209/CFCL.60932

\title{
Naufragium antequam nauem ascenderem feci: naufragio, escritura y autoejemplaridad en las Epistulae Morales de Séneca
}

\author{
Soledad Correa ${ }^{1}$
}

Recibido: 27 de junio de 2017 / Aceptado: 15 de junio de 2018

Resumen. En este artículo analizaremos dos epistulae de Séneca, la 53 y la 87, que tienen en común el hecho de que ambas se abren con una narración en primera persona singular. La compleja dinámica visual que estas narrationes construyen será clave para la promoción de la ejemplaridad del ego epistolar, en tanto éste montará un espectáculo de sus accidentados progresos en el camino hacia la sabiduría, presentándose al mismo tiempo como actor, espectador y juez de sus propias acciones. Consideramos que a través de estas narrationes, que involucran el motivo literario del naufragio, el ego epistolar se apropia activamente de un dispositivo cultural clave para la construcción de la memoria en Roma: el discurso ejemplar. Teniendo en cuenta que debe haber un monumentum, un registro, que visibilice la acción que se propone como ejemplar (Roller 2004), intentaremos demostrar que a través de la escritura de estas cartas el ego epistolar dirige la atención del lector hacia su propia ejemplaridad.

Palabras clave: Séneca; Epistulae Morales; naufragio; escritura; autoejemplaridad

[en] Naufragium antequam nauem ascenderem feci: shipwreck, writing, and self-exemplarity in Seneca's Epistulae Morales

\begin{abstract}
In this article we will analise two of Seneca's epistulae, 53 and 87, which have in common the fact of beginning with a first-singular person narrative. The complex visual dynamics that these narrationes build will play a key role in the promotion of the epistolary ego's exemplarity, since he will make a spectacle of his uneven progress on the path to wisdom, presenting himself as actor, spectator and judge of his own actions. We claim that through these narrationes, which involve shipwreck as a literary motif, the epistolary ego actively appropriates one Roman cultural device which plays a central role in memory building, the discourse of exemplarity. Taking into account the fact that there has to be a monumentum, a record, that makes visible the deed proposed as exemplary (Roller 2004), we will try to show that by writing these letters the epistolary ego directs the reader's attention to his own exemplarity.
\end{abstract}

Keywords: Seneca; Epistulae Morales; shipwreck; writing; self-exemplarity.

Sumario: 1. Introducción. 2. Naufragio, escritura y autoejemplaridad en la epist.53. 3. Naufragio, escritura y autoejemplaridad en la epist.87. 4. Conclusión. 5. Referencias bibliográficas.

Cómo citar: Correa, S., «Naufragium antequam nauem ascenderem feci: naufragio, escritura y autoejemplaridad en las Epistulae Morales de Séneca», Cuad. Filol. Clás. Estud. Lat. 38.1 (2018), 41-57.

Instituto de Filología Clásica, Facultad de Filosofía y Letras, Universidad de Buenos Aires - Consejo Nacional de Investigaciones Científicas y Técnicas (CONICET).

soledad.correa@conicet.gov.ar 


\section{Introducción}

Uno de los problemas a los que debe hacer frente el estudioso de Séneca es el hecho de que, a pesar de que éste escribió voluminosamente y en primera persona, lo que conocemos sobre su vida es muy poco ${ }^{2}$. Sabemos que nació en Córdoba entre los años 4 y 1 a.C. y que murió en el año 65 d. C. Fue exiliado en Córcega por intrigas en la corte imperial y regresó varios años después a instancias de Agripina para desempeñarse como tutor de Nerón, quien finalmente lo obligaría a suicidarse. Sin embargo, si bien existen notables excepciones en la obra de Séneca, tales como el tratado de Clementia, la sátira Apolocyntosis, que salió a la luz tras la muerte de Claudio, o las lecciones de etiqueta práctica presentes en el tratado de Beneficiis, los textos senecanos guardan por lo regular un marcado silencio respecto de sus condiciones socio-históricas de producción y circulación. Y las Epistulae Morales no son la excepción ${ }^{3}$. Esta es una diferencia central con el epistolario de Cicerón -que, junto con las cartas de Epicuro, es uno de los principales modelos literarios de las cartas de Séneca-: mientras que Cicerón habitualmente sitúa sus obras en un momento específico, Séneca huye con la mayor celeridad posible de lo específico hacia lo abstracto ${ }^{4}$.

Séneca compuso sus Epistulae Morales ${ }^{5}$ al final de su vida, en algún momento entre su retiro de la vida pública como amicus principis en el $62 \mathrm{~d}$. C. y su muerte en el $65 \mathrm{~d}$. $\mathrm{C}^{6}$. Probablemente son su última obra y han sido consideradas como la culminación de su labor filosófica, un intento de sintetizar y transmitir la doctrina estoica sobre cómo vivir bien ${ }^{7}$, doctrina que se encuentra esbozada de manera más difusa en el resto de sus escritos filosóficos, y tratada menos directamente en sus obras dramáticas. Recordemos que recién en la Edad Media la filosofía comenzó a ser concebida como una actividad puramente teórica y que en la Antigüedad la elección de una determinada escuela filosófica presuponía la opción por vivir de cierta manera, opción que exigía del individuo un cambio total de vida y cierto deseo de ser y de vivir de otro modo (Hadot 1998, 13). La preocupación por que exista armonía entre vida y discurso filosófico se encuentra tematizada en el texto de las Epistulae; de hecho, las cartas que analizaremos ponen el foco en las dificultades del ego epistolar para vivir conforme a la doctrina filosófica elegida ${ }^{8}$. Asimismo, hay que tener presente que, si bien en los manuales de historia de la filosofía encontraremos

Cf. Syme (1958, 552): «Without the testimony of Tacitus, Seneca the statesman could hardly exist».

En tal sentido, apunta Henderson $(2004,6)$ : «Referential moments are shockingly rare, as names, locales, dates, and events are either repressed or repeatedly, emphatically, anonymized. [...] Disorientation of the reader is the first objective of the correction programme. Scrubbing the interrogation clean of external coordinates is part of a sensory-deprivation therapy which aims to reconfigure and redirect the new recruit, inside, inside the mind, wherever morals live».

4 Para el subtexto socio-político de las Epistulae pueden consultarse la clásica biografía de Griffin (1992) o, en español, el ensayo de Mangas Manjarrés (2001). Coincidimos con Gunderson $(2015,8)$ en que el hecho de que borrar la política de los textos puede ser considerado en sí mismo como un acto político.

5 Aulo Gelio es el primero en utilizar este título para referirse a las cartas de Séneca (praef.9). Cugusi $(1983,196)$ señala, no obstante, que es probable que el título haya sido empleado por el propio Séneca.

6 Para las fechas de composición y publicación, $c f$. Griffin $(1992,305,348-350,400,418)$. Cf., asimismo, la excelente y clara síntesis de Setaioli (2014).

Para el lugar de las Epistulae en la obra de Séneca y sus planes de escribir una moralis philosophia adicional, de mayor alcance, $c f$. Leeman (1953) y Russell (1974).

8 Todas las escuelas denunciaron el peligro que corre el filósofo si imagina que su discurso filosófico puede bastarse a sí mismo sin estar en armonía con la vida filosófica. Para las relaciones entre vida y discurso filosófico, cf. Hadot (1998, 12-15). 
a nuestro autor entre los principales exponentes del estoicismo de época imperial, Séneca da a la filosofía estoica una forma nueva que no se deriva automáticamente de sus modelos griegos 9 . Asimismo, su filosofía es inseparable de lo que Henderson $(2004,4)$ denomina su carácter 'epistoliterario' («epistoliterary»), es decir, de la forma metafórica en que Séneca expresa los significados. Sin embargo, conviene tener presente en todo momento que las imágenes a las que apela -en nuestro caso, la imagen del naufragio- no son meros elementos ornamentales, sino que poseen una clara finalidad argumentativa, en tanto se hallan insertas en un proyecto de naturaleza filosófica y parenética ${ }^{10}$.

En comparación con la correspondencia ciceroniana, el corpus epistolar senecano es limitado, tanto en su cronología como en cantidad ${ }^{11}$ : ciento veinticuatro cartas en veinte libros han llegado hasta nosotros, todas escritas por Séneca y dirigidas a Lucilio, un miembro del orden ecuestre, procurador de Sicilia, a quien Séneca dedicó también otras dos obras, Naturales Quaestiones y De prouidentia. Sin embargo, debemos tener presente que Aulo Gelio (12.2.3) se refiere a una carta que no ha llegado hasta nosotros procedente del libro vigesimosegundo, hecho que pone en evidencia que la colección que hoy tenemos está incompleta. A pesar de que en un autor «of many genres», según la definición de Ker (2006), el género literario elegido no debería ser desestimado, a menudo este aspecto ha sido oscurecido por lecturas «ensayísticas» de las cartas (Wilson 2001, 165-169). Con todo, la tendencia a considerar las Epistulae Morales como ensayos con fórmulas epistolares adosadas al comienzo y al final de cada carta ha comenzado a revertirse en los últimos años y varios estudiosos han dedicado sus esfuerzos a poner de relieve la fundamental inscripción de la colección en el género epistolar ${ }^{12}$. La cuestión de si las Epistulae constituyen un genuino intercambio de correspondencia o si, por el contrario, son una ficción literaria está aún abierta a discusión ${ }^{13}$; sin embargo, no resulta plausible pensar que las cartas fueran escritas sólo para Lucilio, dada su abarcadora agenda filosófica y su aspiración a alcanzar un público más amplio, e incluso a la posteridad, a quien Séneca dice dirigirse especialmente ${ }^{14}$.

Interesa destacar que tanto la macro-estructura de la colección como las cartas individuales se resisten a una fácil categorización. Parece existir también en las Epistulae una suerte de ordenamiento u organización por libro ${ }^{15}$. Es decir, encontramos que determinados temas se agrupan y se desarrollan, y también vemos que la estructura

$C f$. Inwood $(2005,13)$ : «Seneca stands out for his striking choice to do what I would call primary philosophy (rather than exegetical or missionary work) in Latin»; y, más adelante, «Seneca, much more than Cicero, is thinking creatively and philosophically in Latin» $(2005,20)$.

$10 C f$. Bartsch $(2009,201):$ « [ ...] we will not expect from them doctrinal correctness, but rather the sort of content that will help incipient Stoics to get their thinking 'off the ground' to take (and continue) the steps towards sagehood».

$11 C f$. Wilson $(2001,186)$, quien conjetura que posiblemente la publicación de las cartas de Cicerón a Ático en época neroniana inspiró a Séneca a componer una colección epistolar dirigida a un único destinatario. Las cartas de Cicerón a Ático son más de 400 y abarcan un período de veinticinco años (68 - 43 a. C.).

12 Cf. Cancik (1967), Maurach (1970), Wilson (1987, 2001), Mazzoli (1989).

13 Para una discusión sobre la historia de las opiniones sobre la autenticidad de las cartas, $c f$. Mazzoli (1989) y Graver (1996, 13-24).

14 Cf. Sen. epist. 8.2. Cf., asimismo, Sen.epist.21.5, 22.2, 64.7 y 79.17.

15 Para estudios que demuestran que el epistolario senecano es una obra estructurada a modo de red entrelazada y que, por lo tanto, el orden en que están dispuestas las cartas es significativo, $c f$. Cancik (1967) y Maurach (1970). 
de esta evolución guarda relación con las divisiones en distintos libros. Al igual que en los libros en verso, la progresión de los temas no es obvia ni necesariamente lineal, pues una característica básica de estas cartas es que ninguna tiene un tema único, sino que son internamente heterogéneas. De acuerdo con esto, el tipo de conexión que cada una tiene con otras cartas es sumamente variado. Lo que en una carta puede parecer un elemento secundario, puede ser revisitado más tarde en otra. Más aun, un tema puede regresar mucho más adelante en la colección y no en una carta adyacente ubicada en el mismo libro, según veremos en las cartas que analizaremos.

Nos centraremos aquí en el análisis de dos cartas, la 53 y la 87, que tienen importantes puntos en común, entre los cuales podemos mencionar el hecho de que ambas se abren con una narración en primera persona. Esta anécdota autobiográfica inicial involucra en ambos casos el motivo literario del naufragio y funciona como catalizadora de la reflexión filosófica posterior, a la que se dedica el resto de la carta. Las Epistulae Morales son la obra más rica en detalles personales de todo el corpus senecano, pues existe una suerte de imperativo genérico para la carta y es que ésta debe dejar entrever el ethos del escritor ${ }^{16}$. Sin embargo, en la colección epistolar senecana lo biográfico -sea que se trate de la propia vida del escritor o de sucesos de la vida del destinatario o de otros amici $^{17}$ - sólo irrumpe a condición de que sea ejemplar ${ }^{18}$. De acuerdo con esto, puede pensarse que las narrationes que Séneca utiliza como disparadoras de la reflexión filosófica tienen un carácter doblemente marcado, no sólo porque son escasas, sino también por el lugar que suele asignárseles en la estructura de la carta (el comienzo), según veremos en las dos epistulae que aquí analizaremos ${ }^{19}$. Hay en esto creemos, un intento de captar la atención del lector -cuya seducción reside muchas veces, como señala Barthes (1993, 19), en la puesta en escena de una aparición-desaparición ${ }^{20}$-, para luego conducirlo a la consideración de los problemas filosóficos tratados en cada carta.

Ahora bien, según creemos, a través de estas narrationes -aunque no exclusivamente a través de ellas- el ego epistolar se apropia activamente de un dispositivo cultural clave para la construcción de la memoria en Roma: el discurso ejemplar. Habida cuenta de que debe haber un monumentum, un registro, que visibilice la acción que se propone como ejemplar (Roller 2004), intentaremos demostrar que en estas cartas el ego epistolar ${ }^{21}$ dirige la atención del lector hacia su propia ejemplaridad. Volviendo a las mencionadas narrationes en primera persona, las consideramos muy interesantes no sólo porque son excepcionales en el epistolario, sino también porque nos ofrecen algo para visualizar, en tanto somos conducidos a estas escenas por la

16 Cf. Muñoz Martín (1985, 88). En el De elocutione (227), obra atribuida erróneamente a Demetrio de Falero, se menciona también esta característica de la carta. Sobre este tratado, $c f$. Malherbe (1988).

17 Para hechos de la vida de Lucilio, $c f$. Sen.epist. 28 y 47; para episodios de la vida de otros amici, $c f$., por ejemplo, Sen.epist. 27.5; 30; 55.2-7; 101.

18 En esto se opone explícitamente a Cicerón, cf. Sen.epist.118.1-2. Como apunta Griffin $(1992,5)$, «[...] he is more concerned to offer the public examples of the moral preacher, the pedagogue, the struggling student, the zealous convert, than to portray his real relationship with his addressee Lucilius, or record his own moods»».

19 Para otros ejemplos, cf. Sen.epist.7.3-4; 12.1-3; 18.1-3; 26.1-3; 30; 49.1; 50.2-3; 51.1; 54; 55.1-4; 56.1-2; 57.13 ; 64.1-2; 65.1-2; 66.1-4; 67.1-2; 70.1; 76.1-4; 77.1-9; 80.1-2;83.1-7; 86.14-21; 91.1-3; 101.1-4; 104.1-5; $108.13-23 ; 123.1-2$.

20 Henderson $(2004,34)$ se refiere a estas narrationes como «[...] that engaging trick of first-person narrative».

21 Denominamos así al sujeto lingüístico que se construye en primera persona en el texto de la carta. Se trata, por supuesto, de una configuración discursiva y, como tal, no se confunde con el individuo psicofísico Lucio Anneo Séneca. 
propia escritura, no son solo algo que imaginamos. Según veremos, la compleja dinámica visual que éstas construyen será clave para la configuración de la ejemplaridad del ego epistolar, en tanto éste montará un espectáculo ${ }^{22}$ de sus accidentados progresos en el camino hacia la sabiduría, presentándose al mismo tiempo como actor, espectador y juez de sus propias acciones.

En tanto las epist.53 y 87 presentan al ego epistolar en viaje ${ }^{23}$ y retoman el motivo literario del naufragio, abriremos un breve paréntesis para referirnos a la pregnancia de esta metáfora en el texto que nos ocupa ${ }^{24}$. El viaje por $\operatorname{mar}^{25}$, símbolo de la vida de los hombres comunes ${ }^{26}$, es presentado, ante todo, como un episodio peligroso. De hecho, el naufragio es un motivo ambiguo, según veremos al analizar la epist.87, en general sinónimo de desastre, por ejemplo en la epist.91 ${ }^{27}$. Las tempestades y el naufragio son la suerte habitual de una existencia que no se deja guiar por la sabiduría. La búsqueda de la sabiduría es una travesía ${ }^{28}$, comparable a los viajes de Ulises, según la epist.31.2, y la vida moral abunda en tempestades, en las que las pasiones zarandean el alma, por ejemplo, en Sen.epist.20.1, 28.3 y 88.7. El navío desamparado simboliza, además, el desasosiego de los stulti, que no saben en qué dirección orientar su vida ${ }^{29}$. El viaje no es sólo la imagen de la angustia de la vida, sino que constituye también una experiencia concreta buscada como fuente de alivio por parte de aquellos aquejados por una insatisfacción permanente, algo que se ve claramente en Sen.epist.2.1, donde el desplazamiento en el espacio es estigmatiza$\mathrm{do}^{30}$. Las dos cartas que veremos a continuación presentarán al ego epistolar en toda la cotidiana complejidad y ambigüedad del hic et nunc, en tanto se abrirán con una experiencia negativa que pondrá en primer plano la falta de estabilidad psicofísica de quien escribe.

22 A propósito de la importancia de la dinámica del espectáculo en Séneca, $c f$. Solimano (1991), Bartsch (2006, 183-229) y Gunderson (2015, 74-104).

23 El viaje es una metáfora central en el estoicismo, de ahí que proficientes sea el término técnico que designa a los adeptos a esta escuela. Hablando estrictamente, sin embargo, en tanto la virtud es el único bien y carece de grados, « $[\ldots]$ there is no 'progress' towards virtue, in that the transition from vice to virtue is instantaneous» (Atherton 1993, 53, n.19). Para el tema del viaje en la obra de Séneca, cf. Bouquet (1979), Motto (1984), Jourdan-Gueyer (1991), Motto (1997) y Montiglio (2006). Cf., asimismo, la entrada «chemin» y «voyage» en Armisen-Marchetti (1989, 86-90).

24 Para una relectura moderna de la imagen del naufragio, $c f$. Morrison (2014). Para las imágenes marítimas en la poesía latina, $c f$. De Saint-Denis (1935, 111-136).

25 En la obra de Séneca, el imaginario del viaje por mar, como el del combate, el de la medicina y otras grandes imágenes, presenta la coherencia de un esquema y su simbolismo se articula tanto a nivel de la vida ordinaria como a nivel de la vida moral. Para las imágenes relativas al viaje por mar en Séneca, $c f$. Steyns (1907, 70-87); Armisen-Marchetti (1989, 140-142, 270-271 y 348).

26 Cf. Sen.epist.70.2-4, donde la navegación es imagen de nuestro viaje por este mundo y la muerte es el puerto.

27 Cf., Sen.epist.91.7-8: cogitanda ergo sunt omnia et animus aduersus ea quae possunt euenire firmandus. exilia, tormenta [morbi], bella, naufragia meditare. $C f$., asimismo, Sen.nat.3.28.2, donde se describe el fin del mundo como un naufragio.

28 Para un análisis del vínculo entre filosofía y naufragio, de Lucrecio a Petronio, $c f$. Berno (2015).

29 Cf. Sen.epist.35.4, 52.1, 66.17, 71.27, 74.11, 95.57, 95.62, 120.20.

$30 \quad C f$., asimismo, caelum, non animum mutant, qui trans mare currunt (Hor.epist. 1.11, 27) y Lucr.3.1058-1059: et quaerere semper / commutare locum quasi onus deponere possit; 1068: hoc se quisque modo fugit. 


\section{Naufragio, escritura y autoejemplaridad en la epist.53}

La epist.53 abre el libro sexto e inaugura una serie de cinco cartas que introducen anécdotas tomadas de la vida cotidiana de Séneca, en las que adquiere un relieve particular el tema del viaje ${ }^{31}$. Posee una profunda unidad estructural ${ }^{32}$ y puede subdividirse en tres secciones: relato de la breve travesía por mar de Nápoles a Putéolos y la náusea (§§1-4), las enfermedades del cuerpo y del alma (§§5-8), el regnum de la filosofía como única medicina del espíritu (§§8-12). A su vez, considerada a la luz del paralelo operado entre el ego epistolar y Ulises (§4), esta carta es susceptible de una ulterior subdivisión entre una sección inicial «odiseica» ( $\S 1-4$ : el viaje por mar, la tempestad, el «naufragio», el protagonista que se salva heroicamente a nado) y una conclusión «iliádica» (§12: la acérrima lucha de la filosofía contra los embates de la fortuna $)^{33}$. La carta se abre sin preámbulos epistolares o referencias al destinatario, $\mathrm{y}$ va directamente al grano:

Quid non potest mihi persuaderi, cui persuasum est ut nauigarem? Solui mari languido; erat sine dubio caelum graue sordidis nubibus, quae fere aut in aquam aut in uentum resoluuntur, sed putaui tam pauca milia a Parthenope tua usque Puteolos subripi posse, quamuis dubio et inpendente caelo. Itaque quo celerius euaderem, protinus per altum ad Nesida derexi praecisurus omnes sinus (Sen.epist.53.1) $)^{34}$.

Como puede apreciarse, se trata de un inicio in medias res, que nos presenta a Séneca ya embarcado y anticipa un desenlace negativo. El políptoton (mihi persuaderi/ cui persuasum est) y la disposición en quiasmo (quid [...] persuaderi/ cui persuasum est) destacan como concepto clave la persuasión, que en esta carta utilizará la anécdota en primera persona como medio, pero apuntará a la promoción del ego epistolar como exemplum. Es notable el hecho de que éste se presenta inicialmente como gubernator, asumiendo su lugar, cuestión que se ve resaltada por estar la mayoría de los verbos en primera persona singular. Asimismo, la clara exposición de las señales que proyectan lúgubres sombras sobre el viaje incipiente hace que, inicialmente, la obcecación sea uno de los rasgos principales que caracterizan al ego epistolar, a lo que se suma la utilización de los verbos subripi y enaderem, que denotan una partida a escondidas, casi un (auto)engaño.

Seguidamente, esta aparente y dudosa calma inicial se esfuma (aequalitas illa quae me corruperat periit, §2) y el mar comienza a agitarse. La reacción del ego epistolar está muy lejos de la característica calma en medio de la tempestad (in media tempestate tranquillitas ${ }^{35}$, propia del sabio estoico:

Coepi gubernatorem rogare ut me in aliquo litore exponeret: aiebat ille aspera esse et inportuosa nec quicquam se aeque in tempestate timere quam terram. Peius autem uexabar quam ut mihi periculum succurreret; nausia enim me segnis haec

31 Nuestro análisis sigue de cerca el excelente y pormenorizado comentario de Berno (2006, 29-111).

32 Coincidimos en esto con Berno (2006, 30-31). Por el contrario, para Motto y Clark (1971), la carta constituye una suerte de stream of consciousness carente de una estructura unitaria.

33 Motto y Clark $(1971,225)$ señalan la impronta de los modelos épicos en la carta, a partir de las referencias a la Odisea y a la Eneida.

34 Seguimos la edición de Reynolds (1965).

35 Cf. Sen.dial.9.14.10. 
et sine exitu torquebat, quae bilem mouet nec effundit. Institi itaque gubernatori et illum, uellet nollet, coegit, peteret litus (Sen.epist.53.2-3).

Como puede verse, la aparición del gubernator deja claro que no era Séneca quien estaba al frente de la nave. Se trata de una figura importante en los textos senecanos ${ }^{36}$, equiparable con el $\mathrm{sabio}^{37}$, o incluso con la propia philosophia, guía severa y rigurosa, según se la presenta más adelante en esta misma carta $(\S \S 9-10)^{38}$. Asimismo, la introducción de este personaje contribuye, por contraste, a la caracterización del ego epistolar, cuya creciente desesperación se ve reflejada en la gradatio ascendente de los verbos que utiliza para dirigirse al gubernator, que van de la cortesía inicial (coepi rogare), continúan con la insistencia sorda ante las objeciones (institi) y llegan incluso a la coacción lisa y llana (coegi). Por el contrario, la respuesta del timonel, de manera breve y categórica, expone claramente los argumentos que desaconsejan el desembarco en una tierra aspera et inportuosa, término este último connotado filosóficamente, en tanto la ausencia de puerto podría sugerir la imposibilidad de liberarse de los males morales ${ }^{39}$. Asimismo, la paradójica afirmación del timonel, nec quicquam se aeque in tempestate timere quam terram, se destaca por su sonoridad -no en vano será retomada más adelante por el ego epistolar $(\S 4)$-, en tanto resalta en ella un tricolon descendente (tempestate timere [...] terram, de cuatro, tres y dos sílabas), acompañado por la triple aliteración de la dental $t$, que se repite también en el interior del primer término (tempestatée), lo que subraya sobre el plano fónico la perturbación del propio timonel ante el pedido de que es objeto. Asimismo, los argumentos que éste presenta destacan la debilidad de las razones del ego epistolar para exigir el desembarco: una simple molestia fisiológica (nausia [...] segnis).

Para referirse al procedimiento necesario para el desembarco, evitando disminuir la tensión narrativa y atenuar el tono dramático con una larga descripción técnica, el ego epistolar recurre a dos citas virgilianas, que describen los dos momentos fundamentales de la maniobra: «las proas se vuelven hacia el mar» (obuertunt pelago proras $^{40}$ ) y «el ancla se arroja desde la proa» (ancora de prora iacitur ${ }^{41}, \S 3$ ). Al mismo tiempo, con estas citas busca reafirmar su menoscabada auctoritas, al destacar el hecho de que él mismo posee la competencia requerida para ejecutar las maniobras necesarias para el desembarco, aunque a un nivel teórico y libresco. Asimismo, el tono épico de estas citas prepara el terreno para el irónico paralelo que se trazará a continuación entre el ego epistolar y Ulises:

memor artificii mei uetus frigidae cultor mitto me in mare, quomodo psychrolutam decet, gausapatus. Quae putas me passum dum per asperas erepo, dum uiam quaero, dum facio? Intelexi non inmerito nautis terram timeri. Incredibilia sunt quae tulerim, cum me ferre non possem: illud scito, Ulixem non fuisse tam irato mari natum ut ubique naufragia faceret: nausiator erat (Sen.epist.53.4).

\footnotetext{
36 A propósito de la figura del gubernator y su valencia metafórica en Séneca, $c f$. Steyns (1907, 76-77), Armisen-Marchetti $(1989,148)$.

Cf. Sen.epist.85.30-36.

Cf., asimismo, Sen.epist.16.3.

A propósito de la simbología del puerto en Séneca, $c f$. Armisen-Marchetti (1989, 153-154).

Verg.Aen.6.3.

Verg.Aen.3.277.
} 
Los grecismos psychrolutam y gausapatus resultan extraños dada la aversión que generalmente se advierte en la obra de Séneca por las palabras de origen extranjero ${ }^{42}$, pero creemos que no desentonan en un contexto «odiseico». Como vemos, la imagen que aquí se presenta del ego epistolar sugiere una grotesca exaltación de su capacidad para soportar la adversidad, resaltada por la presencia del verbo patior y por la reiteración del verbo fero (tulerim, ferre). A esto se añade la anáfora de dum, con los verbos en presente, que actualizan la narratio y muestran al ego epistolar en una suerte de clímax de esfuerzo. Este énfasis anticipa el inminente parangón con Ulises polutlētos. Asimismo, comprobamos aquí que el «naufragio» no es un accidente debido a la suerte, sino que se debe a su exclusiva responsabilidad. Se reitera aquí, seguido del verbo intellexi, el paradojal precepto náutico del gubernator, cuya validez, no obstante, el ego epistolar solo reconoce después de haber experimentado las consecuencias de haberlo desoído. Es notable también la sententia incredibilia sunt quae tulerim, cum me ferre non possem, enmarcada por verbos en antítesis (sunt) non possem), en tanto condensa la condición tragicómica del ego epistolar, capaz de tolerar cosas imposibles (como un héroe) por ser incapaz de tolerarse a sí mismo (como un inepto). Asimismo, el parangón con Ulises da pie para que el ego epistolar emprenda una suerte de «revisionismo mítico», que conduce a una insólita relectura de la Odisea, de acuerdo con la cual todos los naufragios de Ulises, el navegante por excelencia, habrían sido el resultado de una debilidad física, su condición de nausiator, neologismo que constituye un hápax en la literatura latina (Berno 2006, 66) ${ }^{43}$.

Esta narración inicial, que se distingue por el humor y la auto-ironía, ha revelado al lector la condición miserable del escritor, a nivel físico y espiritual, disminuyendo la distancia entre maestro y discípulo, pero al mismo tiempo ha puesto en peligro las credenciales del ego epistolar para promoverse como exemplum. En este sentido, es notable el hecho de que en la carta que precede a la que ahora estamos analizando, el ego epistolar señala que, dado que el camino hacia la sabiduría está plagado de obstáculos, el proficiens ha de buscar ayuda en los exempla que nos ofrecen los antiguos, pero también los presentes. La clave para elegir a alguien de los presentes como exemplum será optar por aquel a quien se admira más por haberle visto que por haberlo escuchado (eum elige adiutorem quem magis admireris cum uideris quam cum audieris, epist. 52.8). Sin embargo, la imagen de sí que nos ha presentado el ego epistolar hasta el momento dista bastante de ser halagüeña.

Ahora bien, el resto de la carta introduce un cisma en el ego epistolar, en tanto éste se desdobla y la escritura de la carta se convierte en ocasión para tomar distancia de sí mismo y ofrecerse a la mirada de los otros. En efecto, tras recuperarse, comienza a meditar sobre la resistencia que tienen los hombres a admitir sus propios males, sean estos físicos o morales: [...] coepi mecum cogitare, quanta nos uitiorum nostrorum sequeretur obliuio, etiam corporalium, quae subinde admonet sui, nedum illorum quae ego magis latent quo maiora sunt (Sen.epist.53.5). Da comienzo así un autoescrutinio, en el que la primera persona singular de los primeros cuatro párrafos cede el paso a la primera persona plural. Se compromete de esta manera al lector, a

42 Cf. Sen.epist.54.1.

43 El juicio de Séneca con respecto a la figura de Ulises es ambivalente, generalmente negativo en las tragedias y positivo en la prosa, donde funciona como una suerte de ícono del sabio estoico (por ejemplo, Sen.dial.2.2.2). Se trata de un personaje dotado de múltiples aristas, de modo que parangonarse con él está lejos de ser una operación de claro autoencomio. Cf. Berno (2006, 64-66). 
quien la experiencia del «naufragio» podía resultarle más o menos ajena. Asimismo, se establece una distancia entre el ego de la anécdota, que actuaba por impulso ( $p u$ taui, §1) y el ego narrador, que en el ahora de la escritura medita sobre lo que le ha sucedido. La reflexión que aquí se expone se ve subrayada por la aliteración presente en coepi [...] cogitare. Como si fuese el protagonista de una novela de formación, con sus reveses, giros imprevistos de la trama y desviaciones del camino, el ego epistolar sale de la anécdota transformado y se muestra capaz de releerla y reinterpretarla como metáfora de la lucha desigual del hombre contra los males del cuerpo y del alma. De esta manera, el autoescrutinio que introduce un cisma en el ego epistolar abre la posibilidad de una autotransformación ${ }^{44}$ en la que, como vemos, la escritura desempeña una función clave.

Así, la anécdota autobiográfica inicial da pie para que el ego epistolar la reformule en términos médico-psicológicos. De acuerdo con esto, señala que las enfermedades del cuerpo son distintas a las del alma en base a la relación entre gravedad y conciencia: en las primeras, a mayor gravedad corresponde mayor evidencia y, por lo tanto, conciencia del mal; en las segundas, a mayor gravedad corresponde menor evidencia ( $\$$ 6-7), pues oscurecen la mente como un sueño profundo (grauis sopor, §7). En la raíz de los uitia hay, pues, un problema de conocimiento, dado que el hombre no sabe o no quiere saber que es vicioso, por lo tanto, no intenta siquiera curarse y la enfermedad se agrava. La curación de los uitia comienza con un examen de conciencia, ejercicio espiritual ${ }^{45}$ del que esta carta nos ofrece un claro ejemplo:

Quare uitia sua nemo confitetur? quia etiamnunc in illis est: somnium narrare uigilantis est, et uitia sua confiteri sanitatis indicium est. Expergiscamur ergo, ut errores nostros coarguere possimus. Sola autem nos philosophia excitabit, sola somnum excutiet grauem: ille te totum dedica (Sen.epist.53.8).

El ego epistolar construye aquí un método para reivindicarse que convierte la narratio (narrare) inicial en prueba (indicium) de que se encuentra libre de faltas. Asimismo, vemos cómo, sobre un mismo referente, los uitia, se solapan tres paradigmas metafóricos: el de la medicina (sanitatis) ${ }^{46}$, el del sueño (somnium, uigilantis, expergiscamur) y el de los procesos judiciales (confitetur, coarguere). El empleo del verbo dedica para referirse a la actividad filosófica, en tanto es propio del lenguaje cultual y religioso, preludia la inminente divinización de la filosofía, que ocupará el resto de la carta, cuyo tono épico final constituye un digno contrapunto «iliádico» del exordio «odiseico». En efecto, el cierre de la carta nos ofrece una filosofía hipostasiada, que es equiparada, por su tendencia absolutista, con Alejandro Magno, en tanto ejerce su poder despóticamente sin concesión alguna para con los intereses del neóftito ( $\$ \$ 9-12)$. A nuestro juicio, la pretensión de convertirse en exemplum por parte del ego epistolar se apoya en la exposición del desdoblamiento aquí expuesto, por medio del cual el yo que escribe se niega a confundirse con sus faltas, toma perspectiva con respecto a los objetos de sus temores y se muestra

44 A propósito de los conceptos «autoescrutinio y autotransformación», cf. el ya clásico trabajo de Edwards (1997).

45 Según Hadot $(1998,15)$, los ejercicios espirituales son «[...] las prácticas, que podían ser de orden físico, como el régimen alimentario, o discursivo, como el diálogo y la meditación o intuitivo, como la contemplación, pero que estaban todas destinadas a operar una modificación y una transformación en el sujeto que las practicaba».

46 A propósito de la caracterización de la filosofía como un arte cuasi-médico, $c f$. Nussbaum (1994). 
consciente de su poder de desprenderse de ellos. Evidentemente, el ego epistolar considera que la exposición de sus errores lo ha eximido de haberlos cometido ${ }^{47} \mathrm{y}$ ha restablecido su auctoritas como magister. Eso explica, a nuestro juicio, los numerosos verbos en imperativo dirigidos al lector ${ }^{48}$ que jalonan el final de esta carta, donde el tono parenético se vuelve perentorio y la relación con el destinatario pasa de paritaria a jerárquica.

\section{Naufragio, escritura y autoejemplaridad en la epist.87}

El fracaso del ego epistolar se reitera, según veremos, en la epist. $87^{49}$, que es una carta de extensión considerable (cuarenta y un párrafos, frente a los doce que tenía la carta analizada en el apartado anterior) y muy cargada a nivel doctrinal, especialmente en la segunda parte. Su estructura es bipartita: la primera sección, hasta el párrafo 11, tiene un carácter introductorio y, según un esquema recurrente en el epistolario, que ya vimos en nuestro análisis precedente de la epist.53, a partir de un episodio que tiene al ego epistolar como protagonista, se deducen una serie de consideraciones morales; la segunda parte, del párrafo 12 hasta el final, despliega y discute cinco silogismos estoicos, ligados a la primera parte, pero desarrollados a un nivel conceptual más elevado, relativos a las relaciones entre riqueza y virtud, que buscan demostrar que las riquezas no son bienes, en tanto el único bien es la virtud $(\S \S 12,15,22,28,38)$. Focalizaremos nuestro análisis en la narratio en primera persona presente en esta carta ( $\S 1-5)$, a partir de la cual el ego epistolar buscará promover su propia experiencia como exemplum.

La carta se abre con una afirmación críptica, que será esclarecida con la narración que le sigue: Naufragium antequam nauem ascenderem feci. El significado de esta paradójica frase -como sabemos, la paradoja es un recurso que provoca un extrañamiento intelectual- ha sido objeto de interpretaciones diversas. Por ejemplo, para Garbarino (1997), naufragium debe entenderse como una metáfora de despojamiento en sentido positivo al comienzo de un viaje y no como un símbolo de falta moral; por su parte, Allegri (2004) reafirma el sentido de naufragium como fracaso en el viaje hacia la sabiduría. Con todo, coincidimos con Jones (2014) en que ambas valencias están en juego simultáneamente en esta carta y que mantenerlas, sin cancelar una en detrimento de la otra, puede enriquecer nuestra lectura de este texto.

Tras la desconcertante afirmación inicial, el ego epistolar antepone a la narratio la enseñanza que la experiencia le ha dejado: Interim hoc me iter docuit quam multa haberemus superuacua et quam facile iudicio possemus deponere quae, si quando necessitas abstulit, non sentimus ablata (Sen.epist.87.1). Aquí se oponen dos tipos de pobreza: la primera, producto de una elección deliberada, que requiere iudicium, esto es, una decisión consciente, y que además resulta facile; la segunda, determinada por lo externo, marcada por la ineluctabilidad y la coerción. El primer tipo de pobreza se verá ilustrado en el ejercicio de pobreza voluntaria sobre el que versa la anécdota en primera persona en la que nos detendremos.

47 También en Sen.epist.11.9 se alude a la estrategia de hacer visibles las propias faltas para eliminarlas: Magna pars peccatorum tollitur, si peccaturis testis adsistit [...].

48 Cf. dedica, nega (§8), dimitte et uaca (\$9), conuerte, adside, cole (\$11).

49 Nuestro análisis tiene un fuerte punto de apoyo en la excelente monografía de Allegri (2004). 
A continuación, da comienzo la narratio, donde el ego epistolar actualiza las circunstancias del iter, al presentarlo como aún en curso en el momento de la escritura:

Cum paucissimis seruis, quos unum capere uehiculum potuit, sine ullis rebus nisi quae corpore nostro continebantur, ego et Maximus meus biduum iam beatissimum agimus. Culcita in terra iacet, ego in culcita; ex duabus paenulis altera stragulum, altera opertorium facta est (Sen.epist.87.2).

De este viaje por tierra no se indica la meta, parece tratarse de una suerte de experimento o ejercicio, en el cual dos amigos se han puesto a prueba renunciando voluntariamente a las comodidades y holguras a las que están acostumbrados ${ }^{50}$. Es importante precisar que la exercitatio (en griego, askēsis) era el procedimiento a través del cual los estoicos ponían en práctica lo que habían aprendido a través de la meditatio (Allegri 2004, 13) $)^{51}$, con lo cual, podemos ver que el ego epistolar se presenta en esto como un estoico escrupuloso. En este sentido, precisa que el equipamiento ha sido reducido a lo esencial. El primer signo exterior de austeridad está constituido por el exiguo número de serui, en tanto la multitud de esclavos era sinónimo de luxuria. Otra cuestión a destacar es el hecho de que la práctica de vida sobria asumida por el ego epistolar, lejos de pesarle, le reporta placer (beatissimum). En cuanto al equipaje, nisi quae corpore nostro continebantur, funciona como metáfora de la autárkeia en la confrontación con los embates externos, cuyo ideal está representado en la frase omnia [...] bona mea mecum sunt, atribuido por Séneca a Estilpón de Mégara (Sen. epist.9.18). Otros elementos que componen la escena son, en primer lugar, el lecho colocado sobre la tierra, un hábito al cual se ha preparado siguiendo el exemplum de Átalo, como señala en Sen.epist.108.23 (se trata, evidentemente, de un tipo de colchón relleno, según el uso antiguo, de paja o de caña); en segundo lugar, la manta de la cual el ego epistolar y su amigo hacen uso es un simple mantel de viaje. Este elemento recuerda la caracterización de Diógenes el Cínico, el primero, según un testimonio recogido por Diógenes Laercio, en doblar el mantel para poder dormir dentro (6.22). Como señala Jones $(2014,418)$, un detalle particularmente notable en el inicio de la narratio es la insistencia en mencionar el número dos (ego et Maximus, biduum, ex duabus paenulis), cuestión que funciona, según creemos, como elemento de anticipación de cierta duplicidad, esto es, del conflicto interior que se le generará al ego epistolar al procurar adherir a un doble estándar de conducta.

Mayor espacio se reserva a las características de la comida, según una tradición inveterada en la escuela socrática y el moralismo, donde la alimentación es un elemento caracterizador de las costumbres: De prandio nihil detrahit potuit; paratum

50 El ejercicio de pobreza voluntario es recomendado explícitamente en Sen.epist.18.5-6, donde aparece como una práctica ascética que se aconseja realizar de tanto en tanto para poner a prueba la propia firmeza de ánimo. Asimismo, en Sen.epist.20.12-13 la imaginaria paupertas es preconizada como ejercicio preparatorio necesario para adquirir la capacidad de soportar la verdadera pobreza, no sólo con facilidad, sino incluso con placer. Para Rosivach $(1995,96)$, las epist. son, en su conjunto, un asalto sin tregua al miedo a perder las riquezas materiales.

51 Un texto fundamental para entender la importancia de la exercitatio es Sen.epist.94.47: pars uirtutis disciplina constat, pars exercitatione: et discas oportet et quod didicisti agendo confirmes. La representación de un ejercicio filosófico se arraigaba en el ideal del atletismo y en la práctica habitual de la cultura física en los gimnasios. Al igual que, por medio de ejercicios corporales repetidos, el atleta da a su cuerpo una fuerza y una forma nuevas, así, con los ejercicios filosóficos, el filósofo desarrolla la fuerza de su alma y se transforma a sí mismo. La analogía podía parecer tanto más evidente porque precisamente en el gymnasion, es decir, en el lugar en el que se practicaban los ejercicios físicos, también se impartían a menudo clases de filosofía (Hadot 1998, 208). 
fuit †non magis horat, nusquam sine caricis, numquam sine pugillaribus; illae, si panem habeo, pro pulmentario sunt, si non habeo, pro pane (Sen.epist.87.2-3). El primer rasgo que se pone en evidencia respecto de los alimentos involucra la cantidad y la sobriedad. Si bien Reynolds (1965) considera corrupto non magis hora y lo marca como un locus desperatus, creemos que el texto transmitido puede ser mantenido. De hecho, resulta clara la referencia al escaso empeño que requiere la preparación de la comida. La simplicidad de los alimentos es inmediatamente evocada por el término caricae, especie de higo que toma su nombre de la región oriental de Caria, de donde es típico, pero que también se utiliza para referirse al higo seco, alimento típica y tópicamente de pobres ${ }^{52}$. Este detalle es importante, en vista de la relación entre alimentación y vida espiritual. En efecto, el paralelismo, aliteración y homeóptoton entre nusquam sine caricis y numquam sine pugillaribus subrayan en el plano formal la estrecha conexión entre la simplicidad de la alimentación y la tensión espiritual. Asimismo, en la imagen de sí que proyecta el ego epistolar se destaca su compromiso intelectual a prueba de obstáculos, que aparece fuertemente ligado a la escritura (numquam sine pugillaribus).

Hasta aquí hemos visto que la indiferencia que el ego epistolar despliega frente a todos los elementos que acompañan, con exceso de aparato, la vida cotidiana, destaca el éxito de la empresa, lo que se ve reforzado por el hecho de que los rasgos que se atribuye son tópicos en la representación de la frugalitas. Esto resulta instrumental en tanto crea en el lector la ilusión del progreso moral, ilusión que, sin embargo, es desbaratada súbitamente:

Vehiculum in quod inpositus sum rusticum est; mulae uiuere se ambulando testantur; mulio excalceatus, non propter aestatem. Vix a me obtineo ut hoc uehiculum uelim uideri meum: durat adhuc peruersa recti uerecundia, et quotiens in aliquem comitatum lautiorem incidimus inuitus erubesco, quod argumentum est ista quae probo, quae laudo, nondum habere certam sedem et immobilem. Qui sordido uehiculo erubescit pretioso gloriabitur. Parum adhuc profeci: nondum audeo frugalitatem palam ferre; etiamnunc curo opiniones uiatorum (Sen.epist.87.4-5).

Esta viñeta satírica presenta a un hombre poco dispuesto a abandonar su confortable vida. De esta manera, en el cuarto párrafo, da comienzo la parte dedicada al análisis del comportamiento errado, que tiene la doble finalidad de conducir al lector a la búsqueda de sus causas y, al mismo tiempo, de desplegar las razones de la frase enigmática con la cual se ha abierto la carta. Vemos que aquí, nuevamente, se produce un súbito desdoblamiento en el ego epistolar, en tanto éste toma distancia de sí mismo y convierte a la carta en el escenario donde ofrecer su propia inconsistencia a la mirada de los otros. La percepción de este desdoblamiento se manifiesta en el uso del verbo obtineo, que indica generalmente el esfuerzo de llevar a otro a actuar de modo conforme con los propios proyectos ${ }^{53}$ y que, acompañado del insólito a me, pone en evidencia un conflicto interior, una ausencia de armonía, que revela el fallido cumplimiento del proceso educativo. La voluntad de actuar bien aún no se ha estabilizado, no se ha transformado en una disposición durable, en habitus o bona mens. Como vemos, la desilusión llega en el momento del contacto con los otros, que pone de manifiesto

Cf., por ejemplo, Ov.met.8.676; Hor.sat.2.2.122.

Cf. OLD, s.u. 11 . 
la inestabilidad de la tranquilidad y felicidad antes descriptas. Recordemos que, en las primeras cartas -por ejemplo, en Sen.epist.7- el ego epistolar había advertido sobre el peligro que entraña el encuentro con los otros para quien aún no ha asimilado en su alma los buenos principios. El resurgimiento de la irracionalidad se pone de manifiesto en la emergencia de una forma patológica de $u e r e c u n d i a^{54}$, que muestra al ego epistolar fácilmente sugestionable ante las convenciones sociales. La conciencia de haber adoptado un modus uiuendi diferente del común suscita en él, en el encuentro con los otros, un sentimiento de uerecundia que es calificada como peruersa. Esto pone en evidencia que la duplicidad antes mencionada no involucra sólo la asunción de meras formas exteriores de virtud ${ }^{55}$, sino también la adherencia del ego epistolar a un doble estándar, a un doble sistema de valores, el de la filosofía estoica y el de las convenciones sociales de su tiempo, con la consiguiente escisión que esto provoca. Esta relación de exterioridad del ego epistolar respecto del camino correcto (rectum iter $)^{56}$ se marca muy bien, creemos, en los verbos de lengua con los que se refiere a la filosofía estoica (ista quae probo, quae laudo), que dan cuenta de que la virtud aún es para él algo asequible sólo a nivel de los dichos, pero no de los hechos. Por último, es notable la frase en la cual se compendia el resultado de la experiencia, parum adhuc profeci, que no sólo presenta al ego epistolar como proficiens, cuya condición se caracteriza por la posibilidad de vacilar en el progreso hacia el bien y de recaer en el error, sino que también está construida cuidadosamente en paralelo, mediante paronomasia y homoioteleuton, con la frase críptica con la que se abrió la carta, naufragium [...] feci. Así, en una suerte de composición en anillo (Ringkomposition), profeci aclara la metáfora inicial del naufragio, que es una metáfora especialmente connotada en el estoicismo. Como señala Garbarino (1997, 156), el naufragio tiene carácter tópico en la tradición biográfica de varios filósofos, donde la pérdida de las propias posesiones materiales funciona como catalizador para el descubrimiento de la verdadera riqueza. En efecto, se supone que tanto Aristipo de Cirene, como el maestro de Zenón, Estilpón de Mégara y el propio Zenón, fundador de la escuela estoica, todos tuvieron sus visiones filosóficas tras un naufragio. Aquí, sin embargo, se subraya la ironía de la comparación, pues el naufragio funciona como metáfora de la experiencia fallida del proficiens.

Una vez más, esta anécdota cumple con la finalidad de captar al destinatario, al disminuir la distancia entre maestro y discípulo, pero, al mismo tiempo, hace peligrar las credenciales del ego epistolar para promoverse como exemplum, ya que en ella el magister mismo fracasa en un banal y temporario ejercicio de frugalidad, lo que muestra que no está a la altura de su papel de guía espiritual. Sin embargo, la auctoritas del ego epistolar no se ve menoscabada en lo más mínimo, gracias a que en todo momento el ego que observa, juzga y escribe se escinde del ego protagonista, transformando la exhibición de su fracaso en una estrategia de autolegitimación ${ }^{57}$. En este sentido, es interesante recordar el modo en que se abre Sen.epist.6:

54 A propósito de este tradicional valor romano, remitimos al excelente análisis de Kaster (2005, 13-27). Cf., asimismo, Graver (2007, 56-59).

55 Es notable la intertextualidad interna entre este pasaje y Sen.epist.Ep.5.1: Quod pertinaciter studes et omnibus omissis hoc unum agis, ut te meliorem cotidie facias, et probo et gaudeo, nec tantum hortor ut perseueres sed etiam rogo. Illud autem te admoneo, ne eorum more qui non proficere sed conspici cupiunt facias aliqua quae in habitu tuo aut genere uitae notabilia sint $[\ldots]$.

56 Cf. Sen.epist.8.3.

57 La remisión del ego epistolar hacia su propia experiencia es recurrente desde la primera carta, en tanto es lo que, a nuestro juicio, apuntala su auctoritas como magister: Interrogabis fortasse, quid ego faciam, qui tibi 
Intellego, Lucili, non emendari me tantum sed transfigurari; nec hoc promitto iam aut spero, nihil in me superesse quod mutandum sit. Quidni multa habeam quae debeant colligi, quae extenuari, quae attolli? Et hoc ipsum argumentum est in melius translati animi, quod uitia sua quae adhuc ignorabat uidet; quibusdam aegris gratulatio fit cum ipsi aegros se esse senserunt (Sen.epist.6.1).

El ego epistolar declara aquí que su encuentro con la filosofía no ha sido sin consecuencias, pues ha sido corregido y transformado por ella. Esto es sugerido explícitamente por el componente trans- en transfigurari, que subraya un cambio sustancial, una conversión total de vida, que ocurre cuando la filosofía no es tomada como doctrina sino como método de vida, como habitus animi (Scarpat 1975, 77-8). Si consideramos el papel que la escritura juega en este proceso y recordamos que el epistolario de Séneca fue concebido para ser publicado ${ }^{58}$, resulta interesante también el uso del verbo emendari ${ }^{59}$, que sugiere que el ego epistolar ha sido corregido en su persona, pero también enmendado como un texto.

\section{Conclusión}

La ejemplaridad del ego epistolar no estriba entonces en el hecho de carecer de faltas, sino en su constante autoescrutinio, posibilitado y multiplicado en sus efectos por la escritura, que al tomar como punto de partida la propia experiencia errada de quien escribe busca estimular al destinatario a una autocrítica constante. En este sentido, en todo el epistolario es recurrente la invitación a observarse, a hacer examen de conciencia, en tanto el reconocimiento del error es un momento imprescindible del proceso educativo ${ }^{60}$. Podemos seguir preguntándonos, sin embargo, ¿por qué mostrar-escribir los propios fracasos? En primer lugar, podríamos proponer, porque mostrarse en la adversidad permite encarecer la propia autoimagen ${ }^{61}$. En segundo lugar, porque el autoconocimiento provee el acicate y se convierte en prueba de automejoramiento. Podríamos decir, incluso, parafraseando a Séneca en el diálogo de ira, que quien se acerca a la escritura para cambiar, ya ha cambiado ${ }^{62}$. En efecto, la escritura es un medio privilegiado merced al cual el filósofo puede actuar sobre sí mismo y sobre los demás, pues, si es la expresión de una opción existencial, siempre

ista praecipio (Sen.epist.1.4). Asimismo, la estrategia de confesión de sus propias faltas (Ego certe confitebor imbecillitatem meam, Sen.epist.7.1) lo configura como una particular clase de magister, que aprende mientras enseña (homines, dum docent, discunt, Sen.epist.7.8). Cf. también: “tu me,” inquis, "mones? Iam enim te ipse monuisti, iam correxisti? Ideo aliorum emendationi uacas? [...] Tamquam in eodem ualetudinario iaceam, de communi tecum malo conloquor et remedia communico (Sen.epist.27.1)

58 Cf. Sen.epist.21.5.

59 Cf. $O L D$, s.u.2, «to correct the mistakes or inaccuracies (in a document, etc.), revise or sim.; (esp. literary work intended for publication)». Cf., asimismo, Sen.epist.4.1: Perseuera ut coepisti et quantum potes propera, quo diutius frui emendato animo et composito possis.

$60 C f$., por ejemplo, Sen.epist.16.2: excute te et uari escrutare et obserua. Cf., asimismo, Sen.epist.28.9-10, la cita de la sentencia epicúrea initium est salutis notitia peccati.

${ }_{61} C f$., en este sentido, Sen.dial.6.5.5: Simul cogita non esse magnum rebus prosperis fortem se gerere, ubi secundo cursu uita procedit: ne gubernatoris quidem artem tranquillum mare et obsequens uentus ostendit, aduersi aliquid incurrat oportet quod animum probet. Cf., asimismo, Sen.dial.1.5.9.

62 Cf. Sen.dial.3.2.36.3: speculo quidem neminem deterritum ab ira credideris: quid ergo est? Qui ad speculum uenerat ut se mutaret, iam mutauerat. 
tiene, directa o indirectamente, una función formadora, educadora, psicagógica, terapéutica. Siempre está destinada a producir un efecto, a crear en el alma un habitus, a provocar una transformación del yo y a propagar su exemplum. Presentarse a sí mismo como exemplum supone, además, una orientación hacia el futuro, una esperanza o incluso una expectativa de que otros seguirán el propio camino. Por último, podemos pensar que la escritura de las cartas que hemos analizado, como un deliberado palimpsesto, deja leer los restos de un «naufragio», esto es, de una experiencia fallida, que es rescrita y, con esto, resignificada, a fin de otorgar al ego epistolar un lugar en el ámbito de la ejemplaridad.

\section{Referencias bibliográficas}

Allegri, G. (2004), Progresso verso la virtus. Il programma della lettera 87 di Seneca, Cesena, Stligraf Editrice.

Armisen-Marchetti, M. (1989), Sapientiae facies. Étude sur les images de Sénèque, París, Les Belles Lettres.

Atherton, C. (1993), The Stoics on Ambiguity, Cambridge, Cambridge University Press.

Barthes, R. (1993 ${ }^{10}$ [1973]), El placer del texto y lección inaugural de la cátedra de semiología literaria del Collège de France, México, Siglo XXI.

Bartsch, S. (2006), The Mirror of the Self. Sexuality, Self-Knowledge and the Gaze in the Early Roman Empire, Chicago, The University of Chicago Press.

Bartsch, S. (2009), «Senecan metaphor and Stoic self-instruction», en Bartsch, S. -Wray, D. (eds.), Seneca and the Self, Cambridge, Cambridge University Press, 188-217.

Berno, F. R. (2006), L. Anneo Seneca, Lettere a Lucilio, libro VI, Le lettere 53-56, Bolonia, Pàtron.

Berno, F. R. (2015), «'Naufragar m’è dolce in questo mare'. Filosofi e naufraghi, da Lucrezio a Seneca (e Petronio)», Maia 67.2, 282-297.

Bouquet, J. (1979), «La notion de progrès chez Lucrèce et Sénèque», ALMarv. 6, 13-22.

Cancik, H. (1967), Untersuchungen zu Senecas Epistulae morales, Hildesheim, Olms.

Cugusi, P. (1983), Evoluzione e forme dell'epistolografia latina nella tarda reppublica e nei primi due secoli dell'impero, con cenni sull'epistolografia preciceroniana, Roma, Herder.

De Saint-Denis, E. (1935), Le rôle de la mer dans la poésie latine, París, Klincksieck.

Edwards, C. (1997), «Self-Scrutiny and Self-Transformation in Seneca's Letters», G\&R 44, 23-38.

Garbarino, G. (1997), «Naufragi e filosofi (a proposito dell'epistola 87 a Lucilio)», Paideia $52,147-156$.

Graver, M. R. (1996), Therapeutic Reading and Seneca's Moral Epistles, PhD Dissertation, Brown University, mimeo.

Graver, M. R. (2007), Stoicism and Emotion, Chicago, The University of Chicago Press.

Griffin, M. T. (1992² [1976]), Seneca: A Philosopher in Politics, Oxford, Oxford University Press.

Gunderson, E. (2015), The Sublime Seneca. Ethics, literature, metaphysics, Cambridge, Cambridge University Press.

Hadot, P. (1998), ¿Qué es la filosofía antigua?, México, Fondo de Cultura Económica.

Henderson, J. (2004), Morals and Villas in Seneca's Letters: Places to Dwell, Cambridge, Cambridge University Press. 
Inwood, B. (2005), Reading Seneca: Stoic Philosophy at Rome, Oxford, Clarendon Press. Jones, M. (2014), «Seneca’s Letters to Lucilius: Hypocrisy as a Way of Life», en Wildberger, J. - Colish, M. L. (eds.), Seneca philosophus, Berlín-Boston, De Gruyter, 393-429.

Jourdan-Gueyer, M.A. (1991), «Iter vitae: De l'image du chemin à l'expérience du voyage dans l'ouvre philosophique de Sénèque», en La route: Mythes et réalités antiques: Actes du colloque organicé par l'ARELAD dans le cadre de la MAFPEN, Dijon, Université de Bourgogne, 33-44.

Kaster, R. A. (2005), Emotion, Restraint, and Community in Ancient Rome, Nueva York, Oxford University Press.

Ker, J. (2006), «Seneca, man of many genres», en Volk, K. - Williams, G. D. (eds.), Seeing

Seneca Whole. Perspectives on Philosophy and Politics, Leiden-Boston, 19-41.

Leeman, A. D. (1953), «Seneca's Plans for a Work 'Moralis philosophia' and Their Influence on His Later Epistles», Mnemosyne 6, 307- 313.

Malherbe, A. J. (1988) (ed.), Ancient Epistolary Theorists, Atlanta, Scholars Press.

Mangas Manjarrés, J. (2001), Séneca o el poder de la cultura, Madrid, Editorial Debate.

Maurach, G. (1970), Der Bau von Senecas Epistulae Morales, Heidelberg, Carl Winter.

Mazzoli, G. (1989), «L' 'Epistulae morales ad Lucilium' di Seneca: Valore letterario e filosófico», $A N R W 36 / 2,1823-1877$.

Montiglio, S. (2006), «Should the Aspiring Wise Man Travel? A Conflict in Seneca’s Thought», AJPh 127/4, 553-586.

Morrison, J. V. (2014), Shipwrecked, Disaster and Transformation in Homer, Shakespeare, Defoe and the Modern World, Ann Arbor, The University of Michigan Press.

Motto, A.L. - Clark, J.R. (1971), «Et terris iactatus et alto: The Art of Seneca's Epistle LIII», AJPh 92/2, 217-225.

Motto, A.L. (1984), «The Idea of Progress in Senecan Thought», CJ 79, 225-240.

Motto, A.L. (1997), «Seneca on Restlessness and Inconstancy», Eirene 33, 96-105.

Muñoz Martín, N. (1985), Teoría epistolar y concepción de la carta en Roma, Granada, Universidad de Granada.

Nussbaum, M.C. (1994), The Therapy of Desire. Theory and Practice in Hellenistic Ethics, Princeton, Princeton University Press.

Reynolds, L.D. (1965), L. Annaei Senecae Ad Lucilium epistulae morales 2, 1. XIV-XX, Oxford, Clarendon Press.

Roller, M. (2004), «Exemplarity in Roman Culture: The Cases of Horatius Cocles and Cloelia», CPh 99/1, 1-56.

Rosivach, V.J. (1995), «Seneca on the fear of poverty in the Epistulae Morales», L'Antiquité Classique 64, 91-98.

Russell, D. A. (1974), «Letters to Lucilius», en Costa, C. D. N. (ed.), Seneca, Boston, Routledge and Kegan Paul, 70-95.

Scarpat, G. (1975), Lettere a Lucilio. Libro primo (epp.I-XII). Testo, introduzione, versione e commento, Brescia, Paideia.

Setaioli, A. (2014), «The Epistulae morales», en Damschen, G.- Heil, A. (eds.), Brill's Companion to Seneca: Philosopher and Dramatist, Leiden-Boston, Brill, 191-200.

Solimano, G. (1991), La prepotenza dell'occhio. Riflessioni sull'opera di Seneca, Génova, Università di Genova.

Steyns, D. (1907), Les Métaphores et les Comparaisons dans les Oevures en prose de Sénèque le philosophe, Gand, Près de l'Université.

Syme, R. (1958), Tacitus, Oxford, The Clarendon Press. 
Wilson, M. (1987), «Seneca’s Epistles to Lucilius: A Revaluation», en Boyle, A. J. (ed.), The Imperial Muse, Berwick, Victoria, 102-121.

Wilson, M. (2001), «Seneca's Epistles Reclassified», en Harrison, S. J. (ed.), Texts, Ideas, and the Classics, Oxford, Oxford University Press, 164-188. 